\title{
GASTRIC ACIDITY: RELATION TO VARIOUS FACTORS SUCH AS AGE AND PHYSICAL FITNESS
}

\author{
BY ARTHUR L. BLOOMFIELD AND CHESTER S. KEEFER
}

(From the Department of Medicine, Stanford University Medical School, San Francisco, and the Medical Clinic, Johns Hopkins University, Baltimore)

(Received for publication July 18, 1927)

In previous papers we reported the results of studies of gastric function carried out by means of a standard alcohol test meal (1). The work had two objectives: first, to investigate the diagnostic value of "gastric analysis" and second, to obtain information about certain questions of physiology of the stomach. The present report deals with the relations of gastric acidity to various factors such as age and physical fitness.

Ever since the introduction of test meals as a means of studying the function of the stomach, clinicians have been interested in estimating the acidity of the gastric juice. Certain outstanding facts were soon discovered. It was found, for example, that the degree of acidity varied in different people, and that gastric ulcer was often associated with high acidity, whereas in cancer of the stomach there was absence of "free HCl." The exact diagnostic significance of gastric acidity has, however, never been accurately defined; some observers regard high acidity (hyperacidity) and anacidity as distinct diseases or disorders, while another view is that great variations may exist without any pathological significance.

It seems evident that some of this uncertainty is due to a lack of accurate information about the normal variations of acid secretion, which will be discussed below.

\section{METHODS}

A miscellaneous group of 90 people was studied. Although they were hospital patients many of them were, to all intents and purposes, normal. Others suffered from various disorders, but no one with 
demonstrable organic disease of the stomach, such as cancer, ulcer or pernicious anemia, was included. Desperately ill and moribund patients were also excluded. The acidity of the gastric juice, following stimulation with a standard alcohol test meal, was determined. The procedure has been described in detail (1) and curves of acid secretion have been published (2). In the following charts titratable acidity is expressed in terms of the number of cubic centimeters of $\mathrm{N} / 10 \mathrm{NaOH}$ necessary to neutralize $100 \mathrm{cc}$. of gastric juice; phenolphthalein was used as indicator. It should be specially emphasized that the values herewith presented refer to the highest acidity of the pure gastric juice attained after stimulation. These values are obtained by making allowance for dilution of the gastric juice by the test meal (1). Values from direct titration of test meal specimens are often incorrect and misleading, owing to various errors which have been pointed out elsewhere (2).

\section{RESULTS}

\section{Range of acidity in people without disease of the stomach}

In the present group, titratable acidity of the pure gastric juice varied from $0^{1}$ to 118 . The percentage distribution of the cases according to height of acidity (exclusive of those having an anacidity) is shown in chart 1 . Over 40 per cent of the subjects had an acidity between 60 and 80 , and 60 per cent of the estimations fell between the limits of 50 and 90 . There was no evidence, however, that the people with values of under 50 or over 90 had any disease of the stomach.

In no person, either normal or with gastric disease, have we ever encountered an acidity over 135 . This is in harmony with the observations of others that there is a definite upper limit of acidity which the human stomach can, under no circumstances (3), exceed. The value corresponds approximately to 0.5 per cent $\mathrm{HCl}$.

To obtain further information on this point histamine was employed. The effect of this substance on gastric secretion has been discussed previously (4); suffice it is to say that it acts as a powerful stimulus. People without gastric disease, who showed various degrees of acidity after the alcohol stimulus, were selected; $0.5 \mathrm{mgm}$.

\footnotetext{
Acidity is recorded as 0 when the $\mathrm{pH}$ was above 3.0
} 
of histamine was then injected subcutaneously and the fest was repeated. The results are shown in table 1.

TABLE 1

Titratable acidity before and after histamine

\begin{tabular}{c|l|c|c}
\hline Case number & Diagnosis & $\begin{array}{c}\text { Titratable acidity } \\
\text { before histamine }\end{array}$ & $\begin{array}{c}\text { Titratable acidity } \\
\text { after histamine }\end{array}$ \\
\hline & Cancer of liver & cc. $0.1 N$ per 100 cc. & cc. $0.1 N$ per $100 c c$. \\
27 & Mitral stenosis & 0 & 0 (pH 3.4$)$ \\
5 & Normal & 0 & 13 \\
69 & Normal & 13 & 67 \\
43 & Hyperthyroidism & 16 & 33 \\
15 & Normal & 43 & 34 \\
65 & Normal & 50 & 65 \\
61 & Normal & 91 & 134 \\
284 & Normal & 81 & 112 \\
13 & & & 124 \\
\hline
\end{tabular}

SOPERCENT OFGROUP

40

30

20

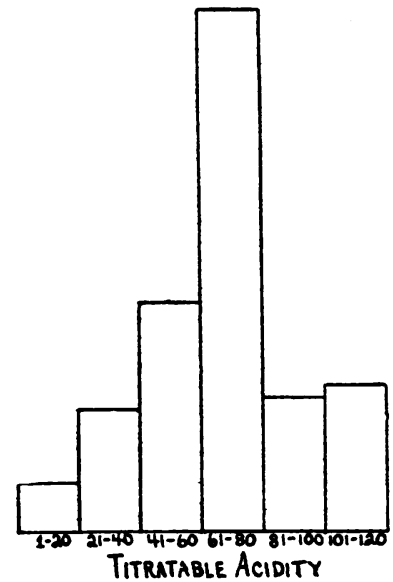

Chart 1. Percentage Distribution of all Cases According to Degree of GASTRIC Acmity

In every case a juice of greater acidity was secreted after histamine. The degree of increase did not, however, bear a constant relation to the value obtained before histamine was given, and the acidity never 
exceeded the upper limit which has previously been mentioned. It is evident then, that the acidity of the gastric juice is in no sense a physiological constant to be compared, for example, with the reacton of the blood. Why one person secretes a more acid juice than another is not at present known; the point of practical importance is that a very liberal interpretation must be put on acid values in the diagnosis of clinical disorders, and that acidities over the entire range, from 0 to approximately 130 , are compatible with health and with the absence of demonstrable disease of the stomach.

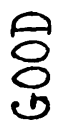

运:
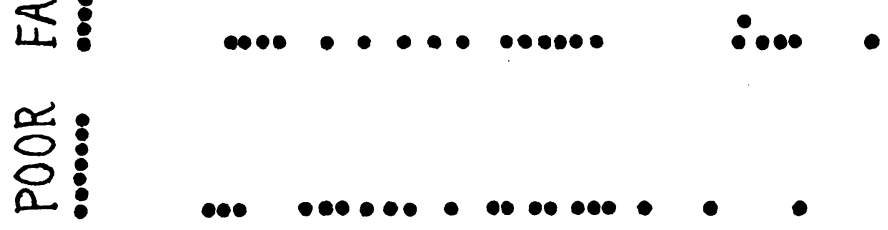

00

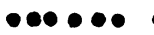

ल8

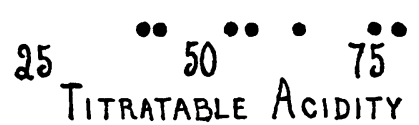

$100^{\bullet} \quad 125$

Chart 2. Relation of Gastric Acidity to Physical Fitness

\section{Relation of gastric acidity to physical fitness}

One wonders, naturally, whether a person's general state of health and well being, apart from disease of the stomach, bears any relation to the degree of acidity of the gastric secretion. Baird, Campbell and Hern (5) have studied this question, and they found no clear relation between degree of acidity and physical fitness. However, they dealt with a group of healthy young adults, who were all well, even though some were of superior physique. The subjects of the present study, on the other hand, represented all degrees of physical condition in a 
miscellaneous group of people who had in common only the fact that there was no demonstrable organic disease of the stomach. Our grouping as to fitness is purely arbitrary: the subjects are divided into four groups (good, fair, poor, bad) depending on our impression of their general physical status. A robust young man with a local lower urinary tract lesion is classed as "good;" a patient with cancer of the liver and cachexia is classed as "bad," etc. The results of the

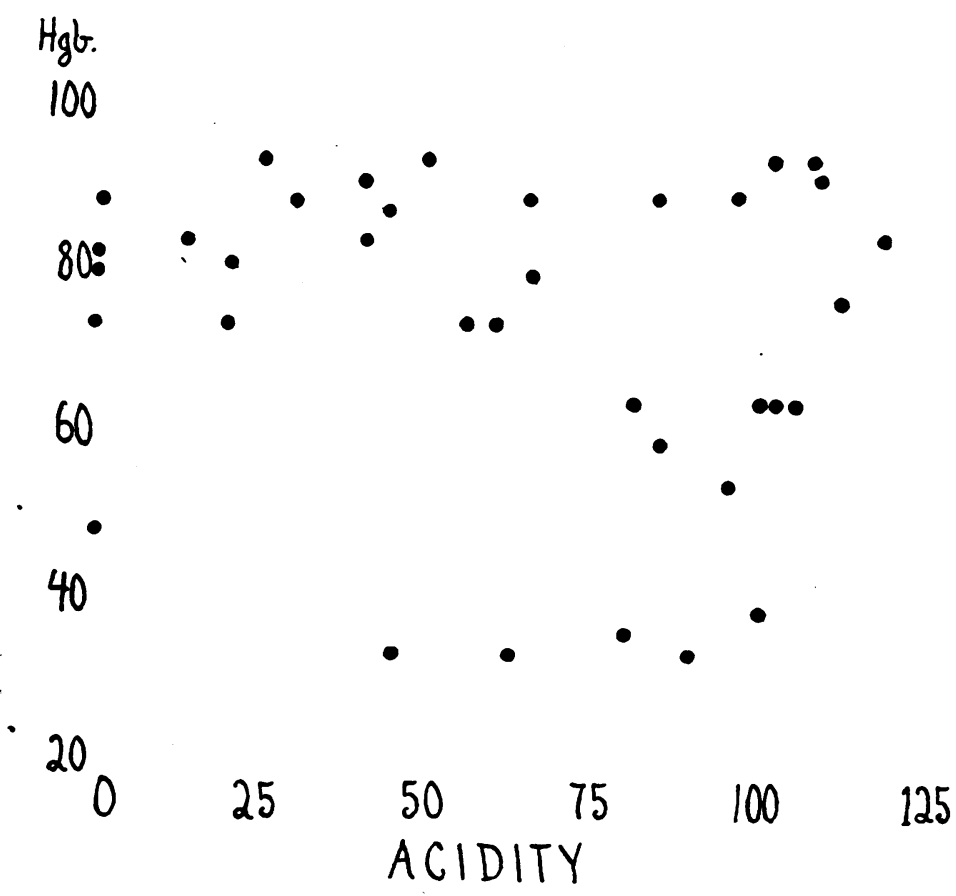

Chart 3. Relation of Gastric Acidity to Hemoglobin

inquiry are shown in chart 2. Each dot represents the highest acidity reached, after the alcohol meal, in a different person. Values from zero up to 100 or more were found in all groups, although more than half of the patients whose physical condition was classed as "bad" had an anacidity. The average acidity of the "good" and "fair" groups combined was 69 and of the "poor" and "bad" 33, so that there appears to be a definite relationship between fitness and 
acidity. However, other factors, such as age, enter into the question and the matter will be discussed below more in detail.

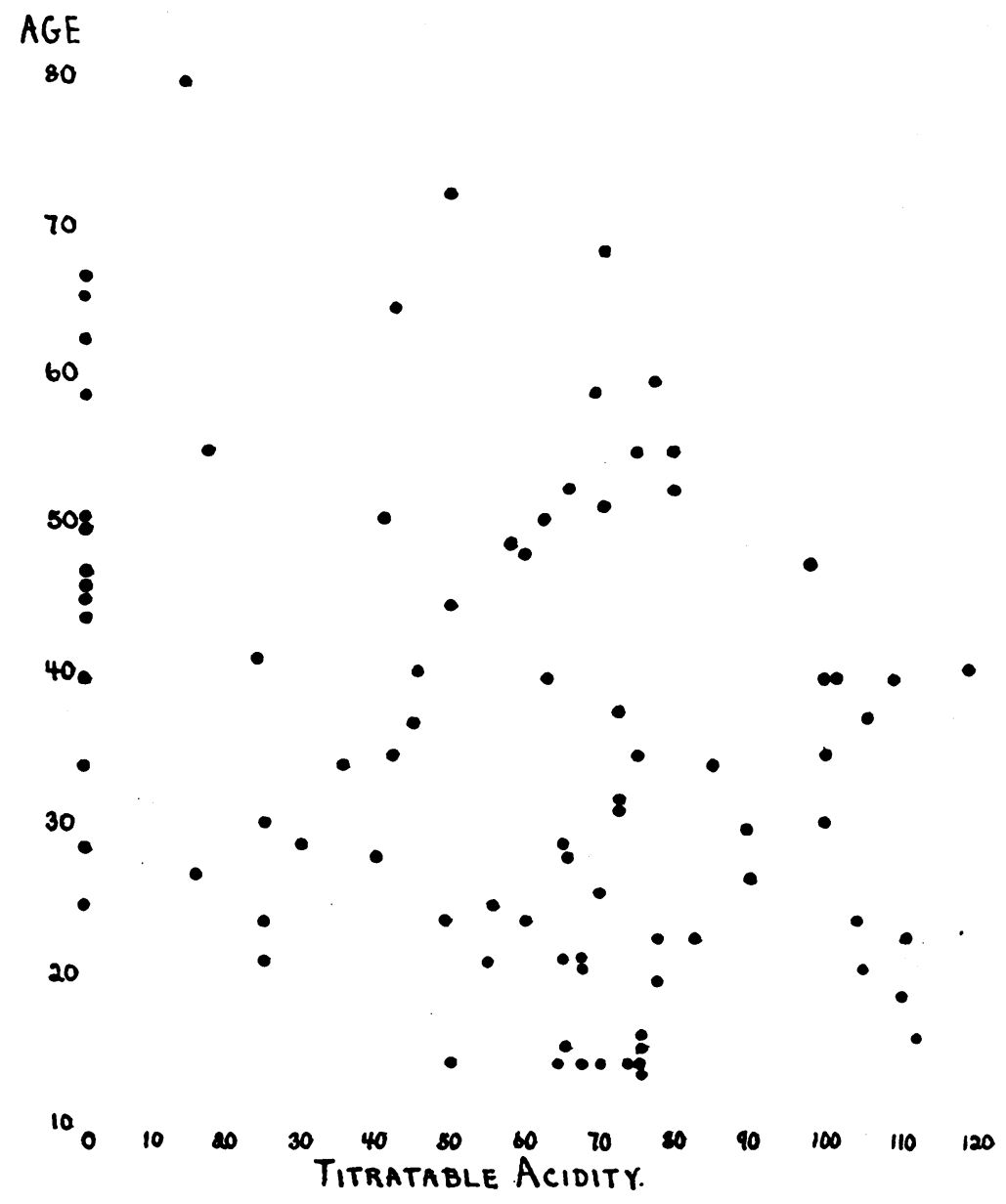

Chart 4. Relation of Gastric Acidity to Age

\section{Anemia}

The relationship of anacidity to pernicious anemia is definitely established; whether lack of blood in itself is associated with defective gastric secretion, is not definitely known. In chart 3 are shown 
some observations in cases other than pernicious anemia. Degree of acidity is plotted against per cent of hemoglobin. Unfortunately we have only a few observations in very anemic patients, but as far

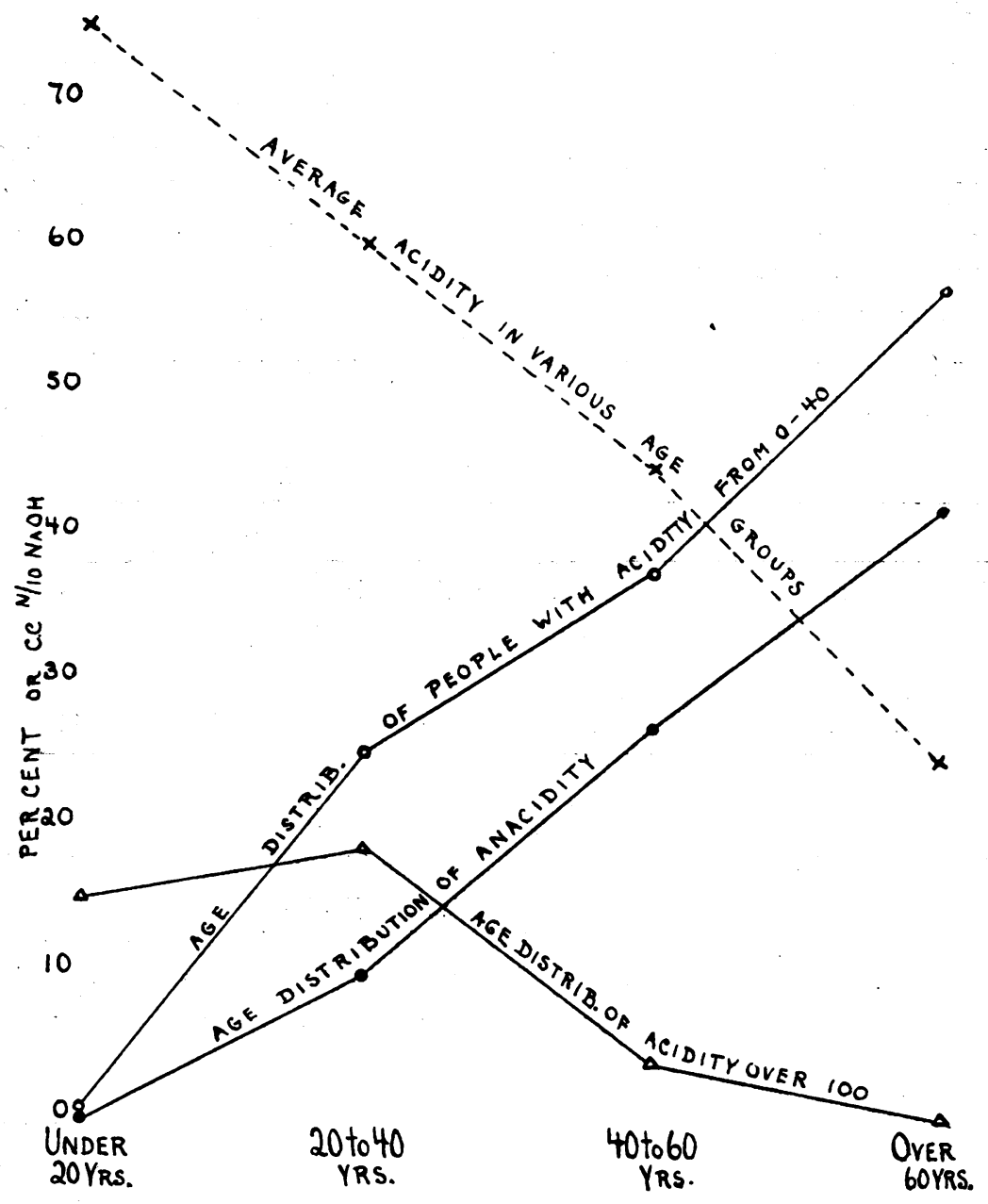

Chart 5. Relation of Gastric Acidity to Age

as they go they give no indication that anemia, per se, is responsible for lack of gastric secretion. More observations are being made on this point. 


$$
\text { Age }
$$

Various observers have shown that gastric secretion is not fully established at birth, and according to Marriott and Davidson (6), and Davison (7), relatively few infants secrete enough $\mathrm{HCl}$ to give the red reaction with dimethyl amido-azobenzene. Between the ages of 15 and 20 years, however, abundant acid is usually present although even among young people approximately 5 per cent fail to show free $\mathrm{HCl}$, when tested with the fractional gruel meal. With advancing years the frequency of "anacidity" increases, and Keefer and Bloomfield (8) found in a large group of people without evidence of any anatomical disease that anacidity (Ewald test meal) was present in over 20 per cent of people in the $50-60$ year age period and in over

TABLE 2

Relation of age and physical fitness to acidity

\begin{tabular}{l|c|c|c}
\hline & All cases & Good & Bad \\
\cline { 2 - 4 } All cases....................... & $\begin{array}{c}\text { Average titratable } \\
\text { acidity } \rightarrow\end{array}$ & 58 & 29 \\
$\begin{array}{l}\downarrow \\
\text { Under } 30 \ldots \ldots \ldots \ldots \ldots \ldots \ldots \ldots \ldots \ldots \ldots \ldots \ldots \ldots\end{array}$ & 65 & 77 & 48 \\
Over $50 \ldots \ldots \ldots \ldots \ldots \ldots$ & 38 & 38 & 16 \\
\hline
\end{tabular}

thirty-five per cent of those beyond 60 years. Dedichen (9) made similar observations. It is not clear, however, from the literature whether the increased frequency of anacidity in old people is merely an expression of a general lessening of secretion of acid in all people as they grow older or whether special causes operate at this time of life to produce deficiency of acid in particular individuals without everyone being affected.

In the present study the highest acidity reached in each case after the alcohol meal was plotted against the age of the subject. The results are shown in chart 4.

At first glance one is struck by the scattering of the dots, which shows that at any age period there is a wide variation in acidity in different people. However, the increasing frequency of anacidity with advancing years is evident, as well as the decrease in high acidities (90 or over). When the average acidity in various age periods is 
charted, a striking general decrease with advancing years is noted. That this is not due merely to more instances of anacidity (chart 5) is shown by charting on the same scale the per cent of the total group with acidities of less than 40 and over 100. These observations suggest the possibility that as the individual grows older his gastric secretion tends to become less acid. If his acidity at the age of 20 was 100 it might, for example, be only 60 at the age of 65 ; if it was 40 in youth there might be an anacidity in old age. In considering the

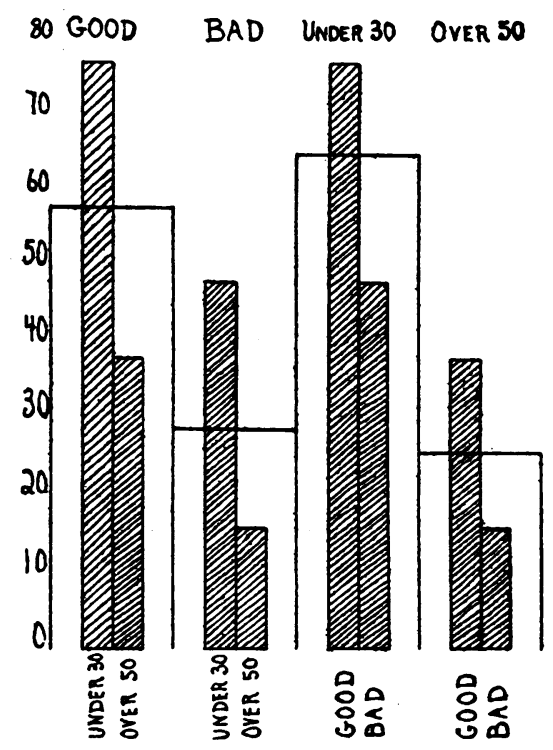

Chart 6. Relation of Age and Physical Fitness to Acidity

relationship of gastric acidity to disease it is therefore necessary to take age into account. This point has already been stressed in relation to anacidity, but is brought out more clearly by the present observations.

In order to be sure that the apparent relation of gastric acidity to age was genuine and was not modified by physical fitness, the figures were analyzed from another point of view. A series of cases was selected in which general physical condition was definitely good or bad. These were further divided into young (under 30 years) and old 
(over 50 years). Both factors were then correlated with average acidity in the various groups. The results are shown in table 2 and chart 6 . Physical condition seems clearly related to degree of gastric acidity, but age as far as the present observations go, is a more important factor.

\section{SUMMARY}

A study has been made of the acidity of the (undiluted) gastric juice after a constant stimulus in a miscellaneous group of patients, none of whom, however, had organic disease of the stomach. The values varied over a wide range but on the whole could be correlated with two factors-age and physical fitness. The former seems the most important, and our observations indicate that as people grow older they tend to secrete a less acid gastric juice. No attempt is made at present to explain the mechanism of the deficiency.

\section{BIBLIOGRAPHY}

1. Bloomfield, A. L., and Keefer, C. S., J. Am. Med. Assoc., 1927, lxxxviii, 707. Clinical Studies of Gastric Function.

2. Bloomfield, A. L., and Keefer, C. S., J. Clin. Invest., 1928, v, 295. Gastric Motilility and the Volume of Gastric Secretion in Man.

3. Carlson, A. J., Physiol. Rev., 1927, iii, 1. The Secretion of Gastric Juice in Health and Disease.

4. Bockus, H. L., and Bank, J., Arch. Int. Med., 1927, xxxix, 508. The Value of Histamine as a Test for Gastric Ulcer.

5. Baird, M. McC., Campbell, J. M. H., and Hern, J. R. B., Guy's Hosp. Rep., 1924, lxxiv, 339. Gastric Secretion, Physique and Physical Fitness.

6. Marriott, W. McK., and Davidson, L. T., Am. J. Dis. Child., 1923, xxvi, 542. The Acidity of the Gastric Contents of Infants.

7. Davison, W. C., Am. J. Dis. Child., 1925, xxx, 23. Gastric Analyses in Normal Infants and in Those Convalescent from Diarrhea.

8. Keefer, C. S., and Bloomfield, A. L., Bull. Johns Hopkins Hosp., 1926, xxxix, 304. The Significance of Gastric Anacidity.

9. Dedichen, L., Acta. Med. Scandinav. Supplement No. 7, 1924-25, xli, 345. Anacidity in Old Persons. 